\title{
Aminoácidos digestíveis verdadeiros de alimentos protéicos determinados em galos cecectomizados
}

\section{Gladstone Brumano1, Paulo Cezar Gomes², Horacio Santiago Rostagno², Luiz Fernando Teixeira Albino², Marlene Schmidt', Rafaela Antônia Ramos Generoso ${ }^{3}$}

\footnotetext{
1 Doutorando em Zootecnia, DZO, UFV, Viçosa - MG.

2 Departamento de Zootecnia, DZO, UFV, Viçosa - MG

${ }^{3}$ Mestrando em Zootecnia, DZO, UFV, Viçosa - MG.
}

RESUMO - Objetivou-se determinar os coeficientes de digestibilidade e os valores de aminoácidos digestíveis verdadeiros de 12 alimentos protéicos para aves. Utilizou-se o método de alimentação forçada, com galos Leghorne adultos cecectomizados, em um delineamento experimental inteiramente casualizado, com 12 tratamentos, seis repetições e um galo por unidade experimental. Os alimentos estudados foram: farelo de glúten de milho $22 \%$, farelo de glúten de milho $60 \%$, concentrado protéico de soja, soja integral extrusada parcialmente desengordurada, farinha de carne e ossos $36 \%$, farinha de carne e ossos $45 \%$, farinha de peixe, farinha de vísceras de aves de alto teor de gordura, farinha de penas, plasma sangüíneo $70 \%$, plasma sangüíneo 78\% e hemácias. Os valores médios dos coeficientes de digestibilidade verdadeira dos aminoácidos essenciais e nãoessenciais, em porcentagem, foram, respectivamente, 83,32 e 87,20 para o farelo de glúten de milho 22\%; 92,90 e 94,86 para o farelo de glúten de milho $60 \%$; 91,10 e 90,19 para o concentrado protéico de soja; 88,90 e 88,91 para a soja integral extrusada parcialmente desengordurada; 88,63 e 85,94 para a farinha de carne e ossos 36\%; 87,80 e 85,00 para a farinha de carne e ossos $45 \% ; 89,39$ e 87,32 para a farinha de peixe; 79,22 e 74,36 para a farinha de vísceras de aves de alto teor de gordura; 85,89 e 82,32 para a farinha de penas; 87,22 e 87,78 para o plasma sangüíneo $70 \%$; 90,42 e 91,40 para o plasma sangüíneo $78 \%$; e 95,25 e 94,31 para as hemácias.

Palavras-chave: aminoácidos digestíveis, digestibilidade, galos cecectomizados

\section{True digestible amino acids of protein meals determined in cecectomized roosters}

\begin{abstract}
The true digestibility coefficients and the values of true amino acid digestibility of 12 protein meals were determined in Leghorn cecectomized roosters by the "forced feed" method. The experiment was analyzed as a complete randomized design with 12 treatments, six replicates and one rooster per experimental unit. The studied feedstuffs were as follows: corn gluten meal $22 \%$, corn gluten meal $60 \%$, soybean protein concentrate, partially defatted extruded whole soybean, meat and bone meal 36\%, meat and bone meal $45 \%$, fish meal, full fatpoultry by-product meal, feather meal, spray-dried plasma $70 \%$, spray-dried plasma $78 \%$ and erythrocytes. The average values of essential and non essential true amino acids digestibility coefficients, in percentage, were as follows: corn gluten meal 22\%, 83.32 and 87.20; corn gluten meal 60\%,92.90 and 94.86 ; soybean protein concentrate, 91.10 and 90.19 ; partially defatted extruded whole soybean: 88.90 and 88.91 , meat and bone meal, 36\%, 88.63 and 85.94 ; meat and bone meal $45 \%, 87.80$ and 85.00 ; fish meal, 89.39 and 87.32 ; full fat poultry by-product meal, 79.22 and 74.36; feather meal, 85.89 and 82.32; spray-dried plasma 70\%, 87.22 and 87.78; spray-dried plasma $78 \%$, 90.42 and 91.40 ; and erythrocytes, 95.25 and 94.31 .
\end{abstract}

Key Words: cecectomized roosters, digestibility, digestible amino acids

\section{Introdução}

Com o aumento da utilização de aminoácidos sintéticos em rações para monogástricos, o uso do conceito de proteína ideal tornou-se mais simples. Os perfis dos aminoácidos na proteína ideal devem ser baseados em valores de aminoácidos digestíveis, sendo necessário determinar os coeficientes de digestibilidade dos aminoácidos nos diferentes alimentos para que se conheça a quantidade desses aminoácidos aproveitada pelos animais. Os coeficientes têm permitido melhor utilização dos alimentos em rações balanceadas para aves, diminuindo os custos de produção e reduzindo a eliminação de poluentes.

Os subprodutos de origem animal têm sido muito utilizados em rações para aves - uma forma de transformar os subprodutos da indústria em proteína de qualidade. A 
grande variação na composição e na qualidade da proteína e dos aminoácidos dos subprodutos de origem animal é o maior inconveniente no uso destes alimentos como ingredientes de rações. A digestibilidade da proteína e dos aminoácidos nesses subprodutos depende da temperatura e do tempo de cozimento, que variam entre os sistemas de processamento, assim como entre a proporção de matériasprimas utilizadas. Essas diferenças foram verificadas por Nascimento et al. (1999), que encontraram grande variação na digestibilidade verdadeira de lisina $(64,05$ a 90,53\%) e de metionina $(73,35$ a $92,56 \%)$ em um estudo com sete tipos de farinhas de vísceras.

Objetivou-se neste trabalho determinar os coeficientes de digestibilidade e os valores de aminoácidos digestíveis verdadeiros de alguns alimentos protéicos para aves.

\section{Material e Métodos}

O experimento foi realizado no Setor de Avicultura do Departamento de Zootecnia (DZO) da Universidade Federal de Viçosa durante o mês de janeiro de 2004.

A digestibilidade verdadeira dos aminoácidos nos alimentos foi determinada pelo método de alimentação forçada, descrito por Sibbald (1979), utilizando-se galos Leghorne adultos cecectomizados, com $2.302 \pm 239$ g. A retirada dos cecos dos galos foi realizada no Setor de Avicultura do DZO utilizando-se a técnica descrita por Pupa et al. (1998), por meio de laparotomia abdominal e anestesia local.

O delineamento experimental foi o inteiramente casualizado, com 12 tratamentos (dois farelos de glúten de milho, soja integral extrusada parcialmente desengordurada, concentrado protéico de soja, duas farinhas de carne e ossos, dois plasmas sangüíneos, hemácias, farinha de vísceras de aves de alto teor de gordura, farinha de peixe e farinha de penas), seis repetições e um galo por unidade experimental, totalizando 72 galos. Simultaneamente, foram mantidos seis galos em jejum para realizar as correções correspondentes às perdas metabólicas e endógenas de aminoácidos.

Os galos foram alojados individualmente em gaiolas para estudos de metabolismo e, inicialmente, foram submetidos a um período de adaptação de cinco dias, com alimentação em dois turnos de uma hora (um pela manhã e outro à tarde), com o objetivo de dilatar o papo. Após o período de adaptação, os galos foram mantidos por 36 horas em jejum para que o trato digestivo fosse totalmente esvaziado, sendo, em seguida, forçados a consumir $30 \mathrm{~g}$ do alimento por meio de funil-sonda introduzido pelo bico até o papo.
A quantidade de alimento fornecido foi dividida em dois períodos ( 15 g cada), um às 8 h e outro às $16 \mathrm{~h}$, para evitar regurgitações.

A coleta total das excretas foi realizada duas vezes ao dia, em intervalos de 12 horas, para evitar fermentação do material sobre as bandejas, que foram revestidas com plásticos para evitar perdas. O período de coletas foi de 56 horas, com início após o fornecimento dos alimentos aos galos. O material recolhido foi armazenado em congelador e, ao final do período experimental, foi descongelado, pesado, homogeneizado e mantido em estufa de ventilação forçada, a $50^{\circ} \mathrm{C}$, por 72 horas, para a pré-secagem. Posteriormente, foram realizadas as análises laboratoriais para determinação dos teores de MS e nitrogênio (N) nas amostras, segundo método descrito por Silva (2002), no Laboratório de Nutrição Animal do DZO. As análises de aminoácidos dos alimentos e das excretas foram realizadas no laboratório da Degussa, na Alemanha.

As temperaturas médias, máxima e mínima, foram de 31 e $22^{\circ} \mathrm{C}$, respectivamente, registradas diariamente utilizando-se dois termômetros de máximas e mínimas, distribuídos aleatoriamente dentro da instalação.

Foram determinados os coeficientes de digestibilidade verdadeira de cada aminoácido dos alimentos utilizando-se os resultados das análises de aminoácidos dos alimentos, das excretas e dos endógenos, por meio da fórmula descrita por Rostagno \& Featherston (1977).

\section{Resultados e Discussão}

Entre os alimentos de origem vegetal estudados, o farelo de glúten de milho $22 \%$ foi o que apresentou os menores valores de aminoácidos essenciais e não-essenciais (Tabela 1) em relação à literatura consultada (Rostagno et al., 2000; NRC 1994, 1998; Rodrigues et al., 2001). Os valores foram semelhantes se comparados aos de Blas et al. (2003), porém, nessa tabela, o glúten apresentou menor valor protéico (20\% PB). Os baixos valores de aminoácidos obtidos nesse alimento podem ter sido conseqüência de seu baixo teor de proteína $(20,18 \%$ PB).

O farelo de glúten de milho $60 \%$ apresentou, de modo geral, valores de aminoácidos semelhantes aos encontrados na literatura (Blas et al., 2003; Fischer Jr. et al., 1998; NRC, 1994;1998; Rodrigues et al., 2001; Rostagno et al., 2000).

A soja integral extrusada parcialmente desengordurada, se comparada à integral extrusada (Café et al., 2000; NRC, 1994; Rostagno et al., 2000), apresentou pouca variação dos valores de aminoácidos totais. Houve maior variação quando comparada à soja integral extrusada citada em Blas et al. 


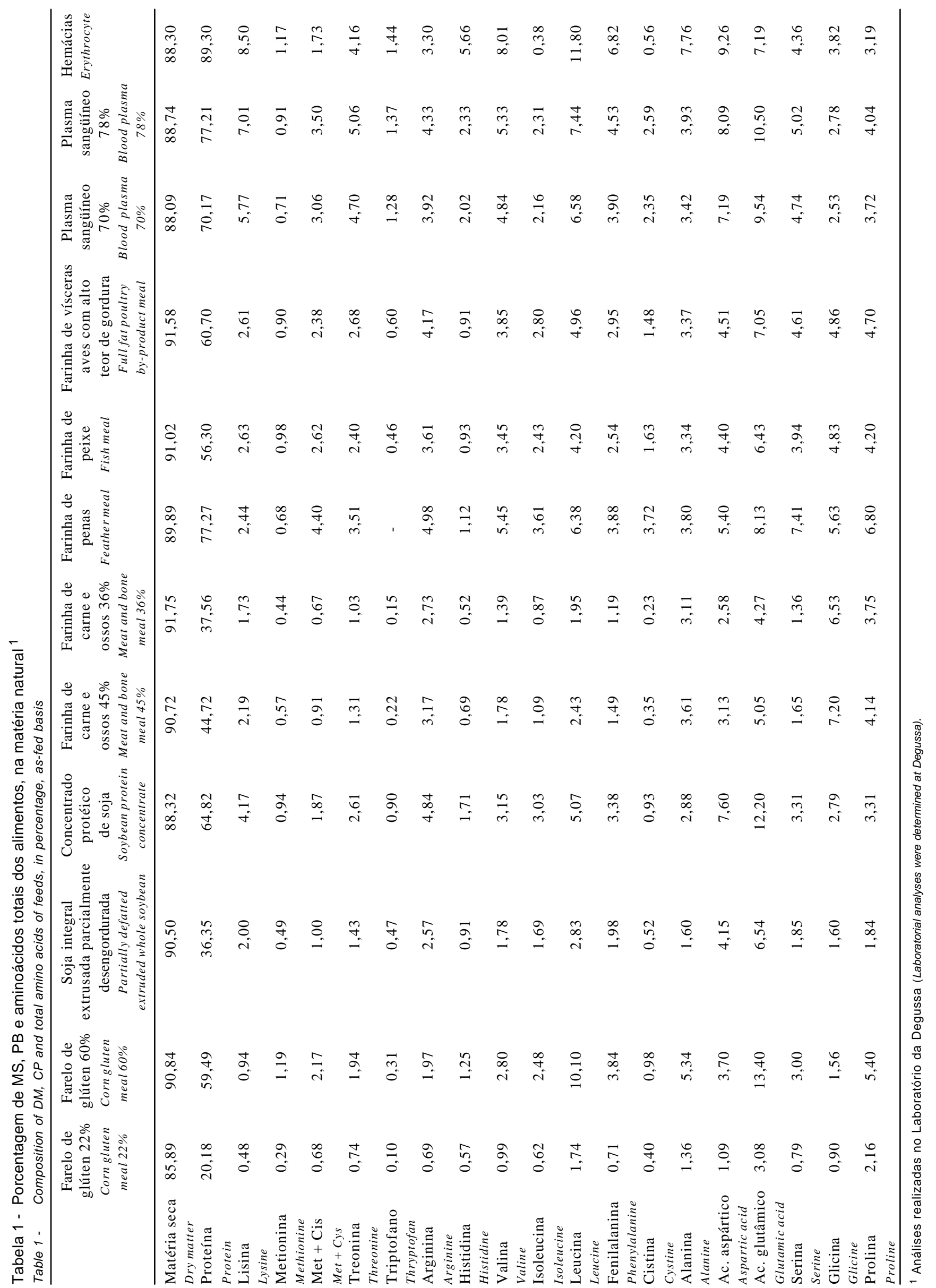


(2003), possivelmente em decorrência das diferentes formas de processamento deste alimento. O concentrado protéico de soja apresentou valores semelhantes aos descritos por Rostagno et al. (2000) e Blas et al. (2003), exceto para o aminoácido arginina.

A composição aminoacídica das farinhas de carne e ossos foi inferior aos valores citados por Rostagno et al. (2000), principalmente para os aminoácidos triptofano e metionina + cistina. Existe grande variação entre os produtos de origem animal, principalmente em virtude das diferentes técnicas de processamento e/ou da falta de padronizaçãodos alimentos (Vieites et al, 2000). A composição aminoacídica da farinha de peixe foi superior aos valores encontrados na literatura para valina, fenilalanina e isoleucina, e inferiores para lisina, metionina e histidina (Albino et al., 1992; EMBRAPA, 1991; Rostagno et al., 2000). Entre os produtos de origem animal avaliados, a farinha de vísceras de aves com alto teor de gordura apresentou, em comparação aos valores descritos na literatura (Bellaver et al., 1998; Blas et al., 2003; NRC, 1994, 1998; Rostagno et al., 2000), as maiores variações na composição de aminoácidos. A composição aminoacídica da farinha de penas, no entanto, foi semelhante à citada por Albino et al. (1992) e Rostagno et al. (2000).

Os plasmas sangüíneos e as hemácias também apresentaram resultados variáveis quando comparados aos valores descritos por Blas et al. (2003). O alimento hemácias é pouco utilizado na alimentação de aves no Brasil, mas apresentou boa composição aminoacídica, semelhante à farinha de sangue spray-dried, citada no NRC (1994 e 1998), exceto para cistina e isoleucina, cujos valores foram inferiores no alimento hemácias.

Os coeficientes de digestibilidade dos aminoácidos dos alimentos testados são apresentados na Tabela 2.

Entre os produtos de origem vegetal, o farelo de glúten de milho $22 \%$ apresentou os menores coeficientes de digestibilidade verdadeira dos aminoácidos (CDVaa), superiores aos encontrados por Rodrigues et al. (2001), o que pode estar associado ao alto teor de fibra desse alimento. De acordo com Coon (1991), a fibra pode alterar os valores de digestibilidade, em virtude das alterações na excreção endógena dos animais. O farelo de glúten de milho $60 \%$ apresentou CDVaa semelhante aos encontrados por Rodrigues et al. (2001). A soja integral extrusada parcialmente desengordurada, quando comparada à soja integral extrusada, apresentou CDVaa semelhante aos descritos por Café et al. (2000) e Fischer Jr. et al. (1998). O concentrado protéico de soja apresentou valor médio de CDVaa alto, comprovando ser uma excelente fonte de proteína e aminoácidos para aves.
As farinhas de carne e ossos tiveram CDVaa superiores à maioria dos valores citados por Vieites et al. (2000), ao av aliarem seis amostras de diferentes origens deste alimento. Entre todos os alimentos avaliados, os menores CDVaa foram encontrados na farinha de vísceras de aves de alto teor de gordura. A composição desse alimento, assim como dos demais produtos de origem animal, possui grande variação, o que explica as diferenças entre os trabalhos.

A farinha de peixe e a farinha de penas apresentaram CDVaa superiores aos encontrados por Albino et al. (1992).

O alimento hemácias apresentou, entre os alimentos estudados, os maiores CDVaa, sendo seguido do plasma sangüíneo $78 \%$. Os CDVaa do plasma sangüíneo $70 \%$ foram inferiores aos encontrados por D'Agostini et al. (2001).

Os valores de aminoácidos digestíveis para o farelo de glúten de milho $22 \%$ foram baixos (Tabela 3 ), o que era esperado, pois os valores de aminoácidos totais nesse alimento foram baixos, mesmo que os CDVaa tenham sido melhores que os obtidos por Rodrigues (2001). A menor variação entre os valores de aminoácidos digestíveis em relação à literatura consultada (Blas et al., 2003; Fischer Jr. et al., 1998b; Rodrigues et al., 2001; Rostagno et al., 2000) foi observada para o farelo de glúten de milho $60 \%$, comprovando a boa padronização na fabricação desse alimento.

Os valores de aminoácidos digestíveis da soja integral extrusada parcialmente desengordurada foram semelhantes aos da soja integral extrusada descritos por Fischer Jr. et al. (1998), exceto para a lisina, que foi inferior, e para a metionina, que foi superior. Entre os produtos de origem vegetal estudados, o concentrado protéico de soja apresentou, em média, os maiores valores de aminoácidos digestíveis revelando-se excelente fonte desses nutrientes.

De modo geral, os valores de aminoácidos digestíveis para as farinhas de carne e ossos foram superiores aos observados por Vieites et al. (2000) e inferiores aos citados por Rostagno et al. (2000).

A farinha de vísceras de aves com alto teor de gordura apresentou composição de aminoácidos digestíveis inferior à do subproduto de abatedouro de aves, alimento de matéria-prima semelhante (Bellaver et al., 1998).

A composição de aminoácidos digestíveis da farinha de penas foi semelhante à descrita por Rostagno et al. (2000), enquanto a do plasma sangüíneo $70 \%$ foi inferior à citada por D'Agostini et al. (2001), exceto para isoleucina e fenilalanina, cujos valores foram superiores. A menor variação entre aminoácidos totais e digestíveis dos alimentos testados foi observada para as hemácias, o que justifica os altos coeficientes de digestibilidade desse alimento. 


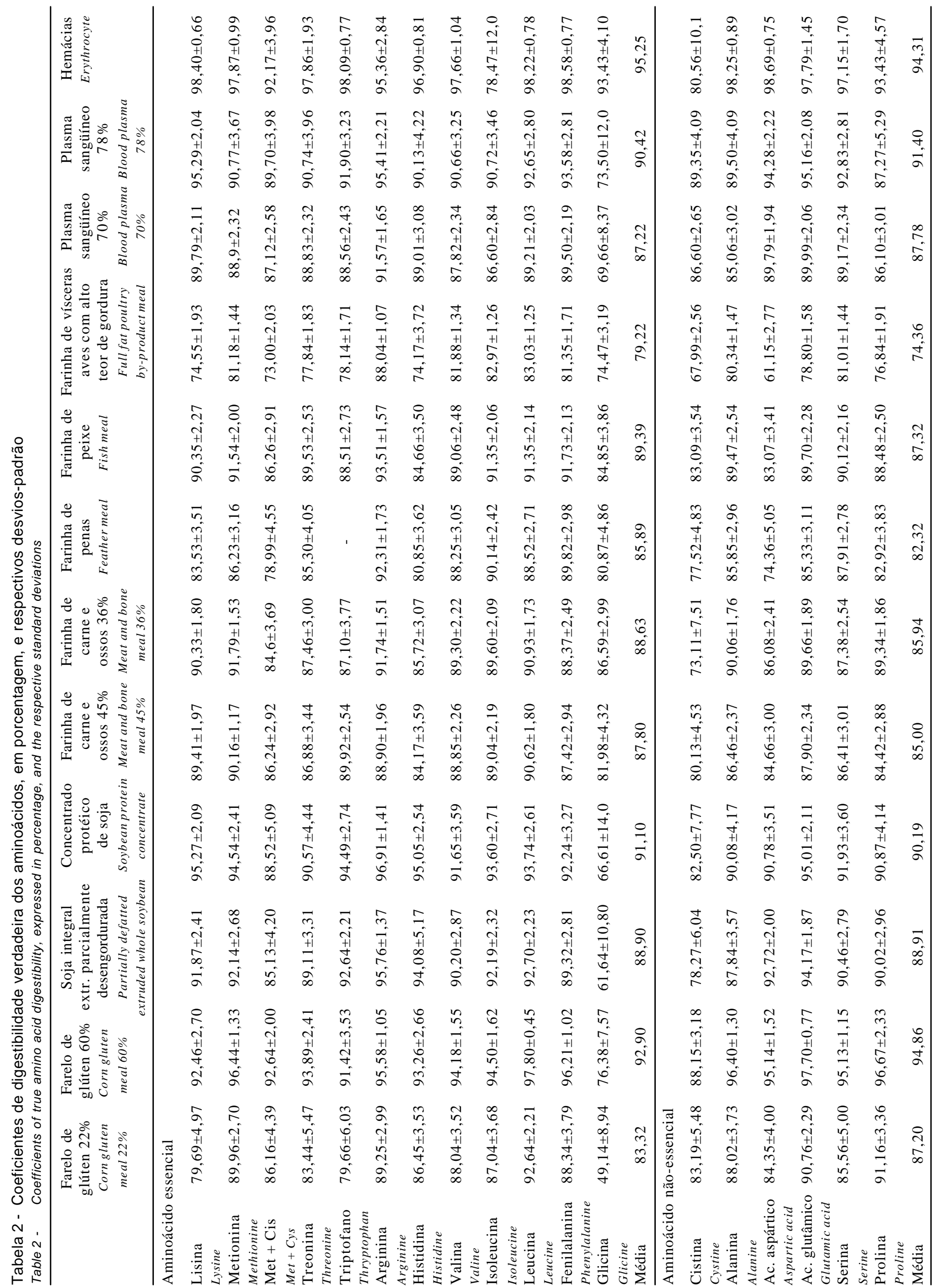




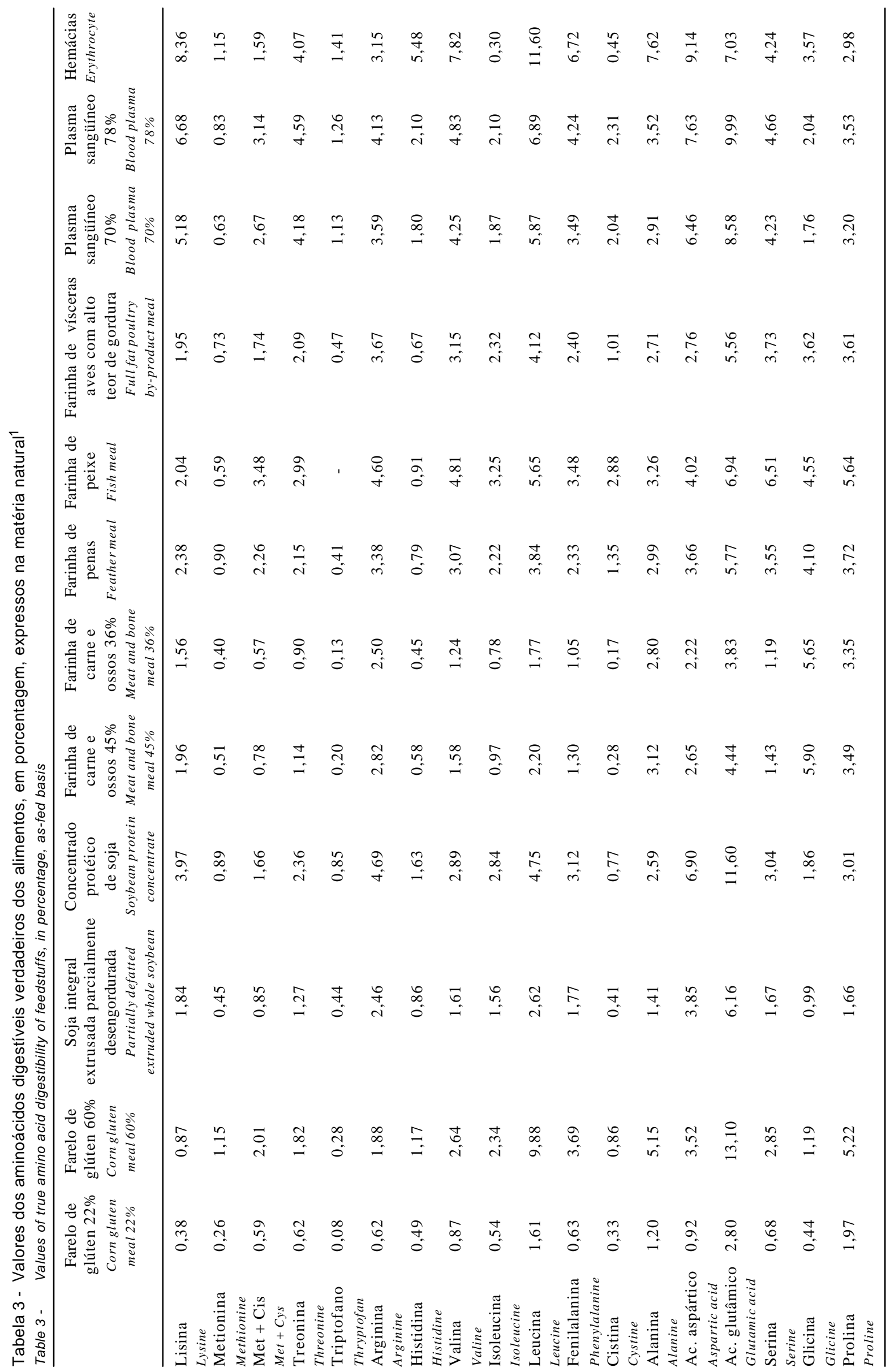




\section{Conclusões}

Os valores médios dos coeficientes de digestibilidade verdadeira dos aminoácidos essenciais e não-essenciais, em porcentagem, foram, respectivamente: 83,32 e 87,20 para o farelo de glúten de milho $22 \%$; 92,90 e 94,86 para o farelo de glúten de milho $60 \%$; 91,10 e 90,19 para o concentrado protéico de soja; 88,90 e 88,91 para a soja integral extrusada parcialmente desengordurada; 88,63 e 85,94 para a farinha de carne e ossos $36 \% ; 87,80$ e 85,00 para a farinha de carne e ossos $45 \%$; 89,39 e 87,32 para a farinha de peixe; 79,22 e 74,36 para a farinha de vísceras de aves com alto teor de gordura; 85,89 e 82,32 para a farinha de penas; 87,22 e 87,78 para o plasma sangüíneo $70 \%$; 90,42 e 91,40 para o plasma sangüíneo $78 \%$; e 95,25 e 94,31 para as hemácias.

\section{Literatura Citada}

ALBINO, L.F.T.; ROSTAGNO, H.S.; FONSECA, J.B. et al. Uso de aminoácidos disponíveis e proteína digestível na formulação de rações para pintos de corte. Revista da Sociedade Brasileira de Zootecnia, v.21, n.6, p.1069-1076, 1992.

BELLAVER, C.; PARSONS, C.; EASTER, R.A. Estimates of true amino acid digestibilities in feed ingredients using precisionfeed, cecectomized roosters. Pesquisa Agropecuária Brasileira, v. 33, n.5, p.731-736, 1998 .

BLAS, C.; MATEOS, G.G.; REBOLAR, P.G. et al. Tablas de composición y valor nutritivo de alimentos para la fabricación de piensos compuestos. 2.ed. Madri: Fundación Española para el Desarrollo de la Nutrición Animal - FEDNA, 2003. 253p.

CAFÉ, M.B.; SAKOMURA, N.K.; JUNQUEIRA, O.M. et al. Composição e digestibilidade dos aminoácidos das sojas integrais processadas para aves. Revista Brasileira de Ciência Avícola, v.2, n.1, p.59-66, 2000.

COON, C.N. Optimizing ingredient utilization through a better understanding of amino acid biovailability. In: TECHNICAL SYMPOSIUM, 1991, Aruba. Proceedings... Aruba: Novus International, 1991. p.11-40.

D'AGOSTINI, P.; GOMES, P.C.; ALBINO, L.F.T. et al. Coeficientes de digestibilidade verdadeira de alguns alimentos determinados com galos cecectomizados. In: REUNIÃO ANUAL DA SOCIEDADE BRASILEIRA DE ZOOTECNIA, 38., 2001, Piracicaba. Anais... Piracicaba: Sociedade Brasileira de Zootecnia, 2001. v.1, p.795-796.
EMPRESA BRASILEIRA DE PESQUISA AGROPECUÁRIA EMBRAPA. Tabela de composição química e valores energéticos de alimentos para suínos e aves. 3.ed. Concórdia: EMBRAPA - Centro Nacional de Pesquisa de Suínos e Aves, 1991. 97p.

FISCHER JR, A.A.; ALBINO, L.F.T.; ROSTAGNO, H.S. et al Determinação dos coeficientes de digestibilidade e dos valores de aminoácidos digestíveis de diferentes alimentos para aves. Revista Brasileira de Zootecnia, v.27, n.2, p.307-313, 1998

NASCIMENTO, A.H.; GOMES, P.C.; ALBINO, L.F.T. et al. Coeficientes de digestibilidade e valores de aminoácidos digestíveis verdadeiros de farinhas de vísceras para aves. In: CONFERÊNCIA APINCO 99, 1999. Anais ... Fundação Apinco de Ciência e Tecnologia Avícolas, 1999. p.27.

NATIONAL RESEARCH COUNCIL - NRC. Nutrient requirements of poultry. 9.ed. Washington, D.C: National Academy of Sciences, 1994. $155 \mathrm{p}$.

NATIONAL RESEARCH COUNCIL - NRC. Nutrient requirements of swine. 3.ed. Washington, D.C: National Academy of Sciences, 1998. $189 \mathrm{p}$.

PUPA, J.M.R.; LEÃO, M.I.; CARVALHO, A.U. et al. Cecectomia em galos sob anestesia local e incisão abdominal. Arquivo Brasileiro de Medicina Veterinária e Zootecnia, v.50, n.5, p.531-535, 1998.

RODRIGUES, P.B.; ROSTAGNO, H.S; ALBINO, L.F.T. Aminoácidos digestíveis verdadeiros do milheto, do milho e subprodutos do milho, determinados com galos adultos cecectomizados. Revista Brasileira de Zootecnia, v.30, n.6, p.2046-2058, 2001 (supl.).

ROSTAGNO, H.S.; ALBINO, L.F.T.; DONZELE, J.L. et al.Tabelas brasileiras para aves e suínos: composição de alimentos e exigências nutricionais. Viçosa, MG: Universidade Federal de Viçosa, 2000. 141p.

ROSTAGNO, H.S.; FEATHERSTON, W.R. Estudos de métodos para determinar a disponibilidade de aminoácidos em pintos. Revista da Sociedade Brasileira de Zootecnia, v.6, n.1, p.64-76, 1977.

SIBBALD, I.R. A bioassay for available amino acids and true metabolizable energy in feedingstuffs. Poultry Science, v.58, p.668-673, 1979.

SILVA, D.J.; QUEIROZ, A.C. Análise de alimentos (métodos químicos e biológicos). 3.ed. Viçosa, MG: Editora UFV, 2002. 235p.

VIEITES, F.M.; ALBINO, L.F.T.; SOARES, P.R. Valores de aminoácidos digestíveis da farinha de carne e ossos para aves. Revista Brasileira de Zootecnia, v.29, n.6, p.2300-2307, 2000 . 